07.2

\title{
Комплексное исследование кластеров радиационных дефектов в GaAs-структурах после нейтронного воздействия
}

\author{
() С.В. Оболенский ${ }^{1}$, Е.В. Волкова ${ }^{1}$, А.Б. Логинов ${ }^{2}$, Б.А. Логинов ${ }^{3}$, Е.А. Тарасова ${ }^{1}$, \\ А.С. Пузанов ${ }^{1}$, С.А. Королев ${ }^{4}$ \\ ${ }^{1}$ Нижегородский государственный университет им. Н.И. Лобачевского, Нижний Новгород, Россия \\ ${ }^{2}$ Московский государственный университет им. М.В. Ломоносова, Москва, Россия \\ 3 Национальный исследовательский университет „МИЭТ“, Зеленоград, Москва, Россия \\ ${ }^{4}$ Институт фризики микроструктур РАН, Афонино, Нижегородская обл., Россия \\ E-mail: obolensk@rf.unn.ru
}

Поступило в Редакцию 2 ноября 2020г.

В окончательной редакции 25 ноября 2020г.

Принято к публикации 26 ноября 2020 г.

\begin{abstract}
Приводятся результаты экспериментальных исследований электрофизических параметров и морфологии поверхности GaAs-структур кольцевых и круговых диодов Шоттки до и после облучения нейтронами с энергией $\sim 1 \mathrm{MeV}$. Методом атомно-силовой микроскопии выявлены объемные радиационные дефекты. По результатам вольт-фарадных измерений определена концентрация электронов и оценена их подвижность до и после облучения. На основе результатов, полученных с применением совокупности данных методов, предложена методика определения средних размеров областей пространственного заряда кластеров радиационных дефектов.
\end{abstract}

Ключевые слова: кластеры радиационных дефектов, вольт-фарадный метод, атомно-силовая микроскопия.

DOI: 10.21883/PJTF.2021.05.50676.18608

Известно, что при воздействии быстрых нейтронов $(\sim 1 \mathrm{MeV})$ в твердом теле помимо точечных дефектов и их комплексов в результате каскадных смещений атомов материала формируются разупорядоченные области - кластеры радиационных дефектов [1]. Такие объекты состоят из субкластеров и окружены областью пространственного заряда (ОПЗ) размером в десятки и сотни нанометров, которая является препятствием для движения электронов [2]. В условиях сокращения размеров активных областей современных полупроводниковых приборов учет морфологии радиационных дефектов становится все более важным для прогнозирования радиационной стойкости приборов наноэлектроники. Характерные размеры кластеров и субкластеров дефектов $(10-100 \mathrm{~nm})[1,3]$ сопоставимы с размерами современных диодов и транзисторов, т.е. вдоль их активных областей может располагаться всего один или несколько кластеров. При этом движение электронов может происходить между кластерами и/или субкластерами дефектов, в том числе и в квазибаллистическом режиме [4], или иметь особенности, свойственные перколяционной проводимости. В этих условиях для моделирования процесса переноса носителей заряда требуется детальная информация о размерах, форме и внутренней структуре кластеров дефектов. Наиболее важным является определение размеров ОПЗ, так как поле пространственного заряда значительно влияет на перенос электронов в облученных образцах.

В настоящей работе приводятся результаты комплексного экспериментального исследования характеристик крупных разупорядоченных областей, образующихся при воздействии нейтронов спектра деления в GaAs. Анализ морфологии кластеров дефектов, определение их количества и размеров в приповерхностном слое $n$-GaAs проводились непосредственно по результатам зондовых измерений на поверхности материала. В отличие от [5] размеры ОПЗ кластеров вычислялись на основе данных об изменении концентрации и подвижности электронов в слоях, прилегающих к поверхности.

Исследуемые структуры $n / n^{-}$-GaAs были изготовлены с использованием газофазной эпитаксии на полуизолирующей GaAs-подложке. Толщина слоя и концентрация атомов донорной примеси составляли соответственно: для $n$-слоя $-90 \mathrm{~nm} \mathrm{и}(3-5) \cdot 10^{17} \mathrm{~cm}^{-3}$, для $n^{-}$-слоя $-500 \mathrm{~nm}$ и $\sim 10^{15} \mathrm{~cm}^{-3}$. Максимум концентрации электронов достигался в средней части $n$-слоя, а подвижность электронов была минимальной $\left(2000-3000 \mathrm{~cm}^{2} /(\mathrm{V} \cdot \mathrm{s})\right)$ в $n$-слое и увеличивалась до $4000-5000 \mathrm{~cm}^{2} /(\mathrm{V} \cdot \mathrm{s})$ в $n^{-}$-слое. На структурах были сформированы кольцевые и круговые диоды, содержащие барьер Шоттки. Радиус круговых контактов Шоттки варьировался от 50 до $30 \mu \mathrm{m}$, зазор кольцевого контакта для тестовых диодов 7 и 8 составлял 9 и $40 \mu \mathrm{m}$ соответственно (рис. 1). Емкость перехода металл-полупроводник в исследуемых диодах при нулевом напряжении смещения составила от 5 до $500 \mathrm{pF}$. Для удобства измерений и снижения их погрешности комплект диодов объединялся в тестовый объект, предназначенный для определения профилей распределения электронов по глубине и оценки их подвижности. Методика проведения измерений обеспечивала низкую погрешность за счет компенсации погрешностей 

(20 образцов)

Результаты измерений распределений по глубине концентрации и подвижности электронов в исследуемых структурах

\begin{tabular}{|c|c|c|c|c|}
\hline \multirow{2}{*}{ Параметр } & \multicolumn{2}{|c|}{ Концентрация } & \multicolumn{2}{|c|}{ Подвижность } \\
\hline & без отжига & с отжигом & без отжига & с отжигом \\
\hline $\begin{array}{c}\text { Положение максимума (для } \\
\text { концентрации) и минимума (для } \\
\text { подвижности) по глубине слоя } \\
\text { после облучения, a.u. }\end{array}$ & 87 & 95 & 72 & 96 \\
\hline $\begin{array}{c}\text { Значение максимума (для } \\
\text { концентрации) и минимума (для } \\
\text { подвижности) после облучения, } \\
\text { a.u. }\end{array}$ & 64 & 98 & 69 & 98 \\
\hline $\begin{array}{c}\text { Среднее значение в слое после } \\
\text { облучения, a.u. }\end{array}$ & 55 & 85 & 65 & 93 \\
\hline
\end{tabular}

Примечание. Приведено значение в процентах от исходного.

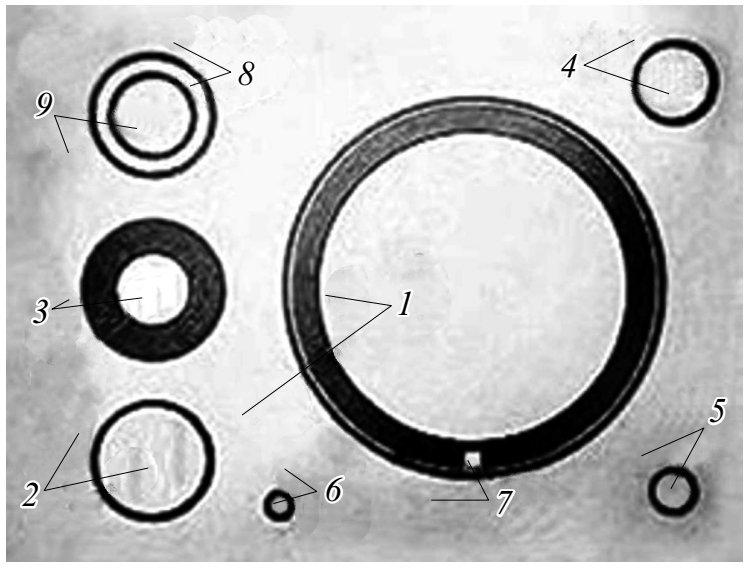

Рис. 1. Исследуемый тестовый объект с круговыми и кольцевыми диодами Шоттки. Размеры диодов от 9 до $300 \mu \mathrm{m}$. Цифрами обозначены пары контактов, которые использовались для измерений.

путем сопоставления результатов измерений на диодах с различными размерами [6]. Конструкция образцов позволяла исследовать микрорельеф поверхности полупроводникового материала в зазорах между контактами (рис. 1) до и после радиационного воздействия.

Толщина проводящего $n$-слоя исследуемой структуры была сопоставима с размерами крупных кластеров радиационных дефектов $(\sim 100 \mathrm{~nm})$ [4] и их областей пространственного заряда $(\sim 30 \mathrm{~nm}$ согласно модели Госсика [2]), поэтому можно считать, что их поверхностная плотность, измеренная с помощью методики атомно-силовой микроскопии (АСM), соответствовала таковой в самом легированном слое. Для контроля влияния точечных дефектов и мелких кластеров, которые „не видны“ на поверхности материала, часть образцов подвергалась отжигу.

Для концентрации примесей $5 \cdot 10^{17} \mathrm{~cm}^{-2}$ характерное расстояние между ионами доноров составляет
$12-13 \mathrm{~nm}$, так что внутри крупных кластеров радиационных дефектов (>100 nm) нейтрализуется до 1000 ионов доноров, а субкластеры с размером $10-20 \mathrm{~nm}$ „Поглощают“ только один донор. Более мелкие субкластеры $(\sim 5 \mathrm{~nm})$ могут размещаться в промежутке между донорами, но влиять на них посредством ОПЗ. Таким образом, кластеры дефектов вместе с их ОПЗ „выкусывают“ области объемом $V_{0}$, так что статическая проводимость слоя $g_{s t}$ уменьшается пропорционально нарушенному объему $V$

$$
g_{s t} \sim V\left(1-\exp \left[-D V_{0} S / V\right]\right),
$$

где $D$ - доза облучения, $S-$ площадь образца [7]. АСМ дает информацию об объеме кластеров без ОПЗ, так что сопоставление результатов позволяет определить ширину ОПЗ.

Измерения проводились до и после нейтронного облучения спектра деления (энергия $0.01-3 \mathrm{MeV}$, средняя энергия около $1 \mathrm{MeV}$, колоколообразный спектр); флюенс составлял $0.5 \cdot 10^{15} \mathrm{~cm}^{-2}$, облучение изотропно по направлению. Образцы размещались в специальных контейнерах для транспортировки и облучения. Каждый исследуемый образец упаковывался отдельно в специальный пакет, во время проведения эксперимента по облучению образцы не извлекались из контейнеров. С помощью оптического микроскопа проводился контроль чистоты поверхности исследуемых структур и анализировались механические повреждения структур как до, так и после облучения. Были проведены две серии измерений: 1) до и после облучения; 2) до и после облучения и последующего отжига дефектов с помощью быстрого (5 min) разогрева до температуры $200^{\circ} \mathrm{C}$ и выдержки около суток с плавным снижением температуры до комнатной.

Измерение зависимости концентрации электронов по глубине проводилось вольт-фарадным методом по методике, предложенной в работе [6]. Результаты измерений приведены в таблице. Видно, что концентрация и подвижность существенно меняются после облучения, но 

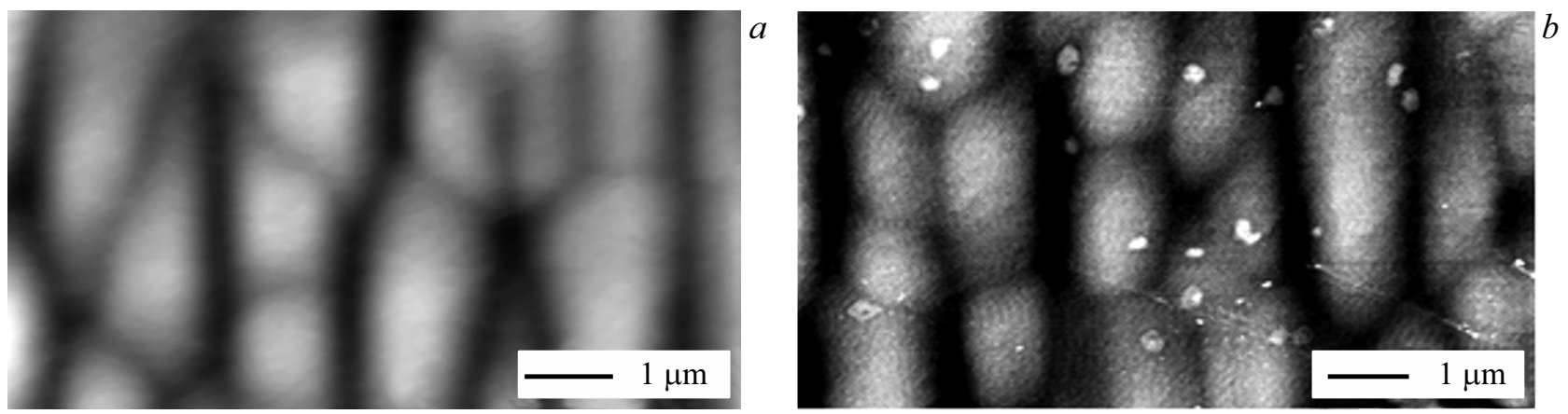

Рис. 2. Характерный вид микрорельефа поверхности GaAs до $(a)$ и после $(b)$ воздействия быстрых нейтронов.

их значения могут быть почти полностью восстановлены отжигом точечных дефектов и мелких кластеров.

Для исследований микрорельефа поверхности GaAs до и после воздействия быстрых нейтронов использовался сканирующий зондовый микроскоп „СММ-2000“ (изготовитель - АО „Завод ПРОТОН“, Зеленоград, www.microscopy.su). До измерений образцы закреплялись на специальной ламели так, чтобы их можно было позиционировать при повторных измерениях (после облучения) с погрешностью не хуже 10-20 $\mu \mathrm{m}$; таким образом, зонд микроскопа попадал в ту же область, что и при измерениях до облучения [8]. Это позволяло надежно констатировать наличие нарушений на поверхности образцов.

Кадры топографии поверхности в области GaAs-колец диодов и транзисторов (рис. 1) получены в режиме АCM. В качестве зондов использованы кантилеверы с радиусом закругления острия $2 \mathrm{~nm}$ марки „MSNL“ фирмы Brucker (США). Достигаемое латеральное разрешение до $2 \mathrm{~nm}$, по высоте - до $0.1 \mathrm{~nm}$. Для одновременного с изучением рельефа снятия карт электропроводности исследуемой поверхности с разрешением до $5 \mathrm{~nm}$ применялись также проводящие кантилеверы RTESPA фирмы Brucker (США) с радиусом закругления острия $8 \mathrm{~nm}$. Дополнительные измерения проводились с использованием кантилеверов с радиусом закругления острия $10 \mathrm{~nm}$ марки NSG30/TiN фирмы NT-MDT. На рис. 2 приведены типичные изображения, полученные при сканировании поверхности GaAs до и после облучения.

Отметим, что качественный вид зерен GaAs coхраняется, при этом на сканах облученного материала появляются дополнительные включения значительно меньшего размера, средняя поверхностная плотность которых составила $1.2 \mu \mathrm{m}^{-2}$. При расчете поверхностной плотности и распределения объектов по размерам учитывались только те, которые состоят не менее чем из девяти точек на изображении, обнаружение более мелких областей считалось недостоверным. Усредненный диаметр кластеров радиационных дефектов рассчитывался как $d=2 \sqrt{\frac{S}{\pi}}$, где $S-$ площадь объекта.
Вероятность $P_{m}$ обнаружения $m$ кластеров радиационных дефектов подчиняется распределению Пуассона

$$
P_{m}=\frac{\left(\langle\sigma\rangle F_{n} V N\right)^{m}}{m !} \exp \left(-\langle\sigma\rangle F_{n} V N\right)
$$

где $F_{n}-$ флюенс нейтронов, $N$ - концентрация атомов вещества, $V$ - объем области, равный произведению исследуемой площади $S$ и усредненной по спектру нейтронов глубины обнаружения кластеров радиационных дефектов $\langle l\rangle$ :

$$
V=S\langle l\rangle=S \int_{0}^{\infty} l(E) f(E) d E,
$$

$l(E)$ - зависимость длины пробега первичного атома отдачи в веществе от энергии нейтронов, $\langle\sigma\rangle-$ усредненное по спектру нейтронов сечение взаимодействия, которое рассчитывается по формуле

$$
\langle\sigma\rangle=\int_{0}^{\infty} \sigma(E) f(E) d E,
$$

$\sigma(E)$ - спектр сечения взаимодействия нейтронов с веществом, $f(E)$ - нормированный спектр нейтронов $\left(\int_{0}^{\infty} f(E) d E=1\right), E-$ энергия нейтронов [9-12]. Расчеты показали, что для площади, равной $1 \mu \mathrm{m}^{2}$, с вероятностью более 0.4 кластер будет обнаружен при флюенсе нейтронов $4 \cdot 10^{14} \mathrm{~cm}^{-2}$ и с вероятностью, близкой к единице, при $8 \cdot 10^{14} \mathrm{~cm}^{-2}$. Это согласуется как с данными зондовой микроскопии, так и с результатами расчетов каскадов столкновений атомов, образующих кластеры дефектов, методом Монте-Карло по известному алгоритмy TRIM [13] (рис. 3).

B результате измерений и расчетов было получено среднее значение величины ОПЗ кластеров, которое составило $37 \mathrm{~nm}$, что несколько больше, чем получается по модели Госсика $(\sim 30 \mathrm{~nm})$. Размер ОПЗ зависел от уровня концентрации электронов и увеличивался до $100 \mathrm{~nm}$ и более в $n^{-}$-слое, проводимость которого снизилась значительно. 

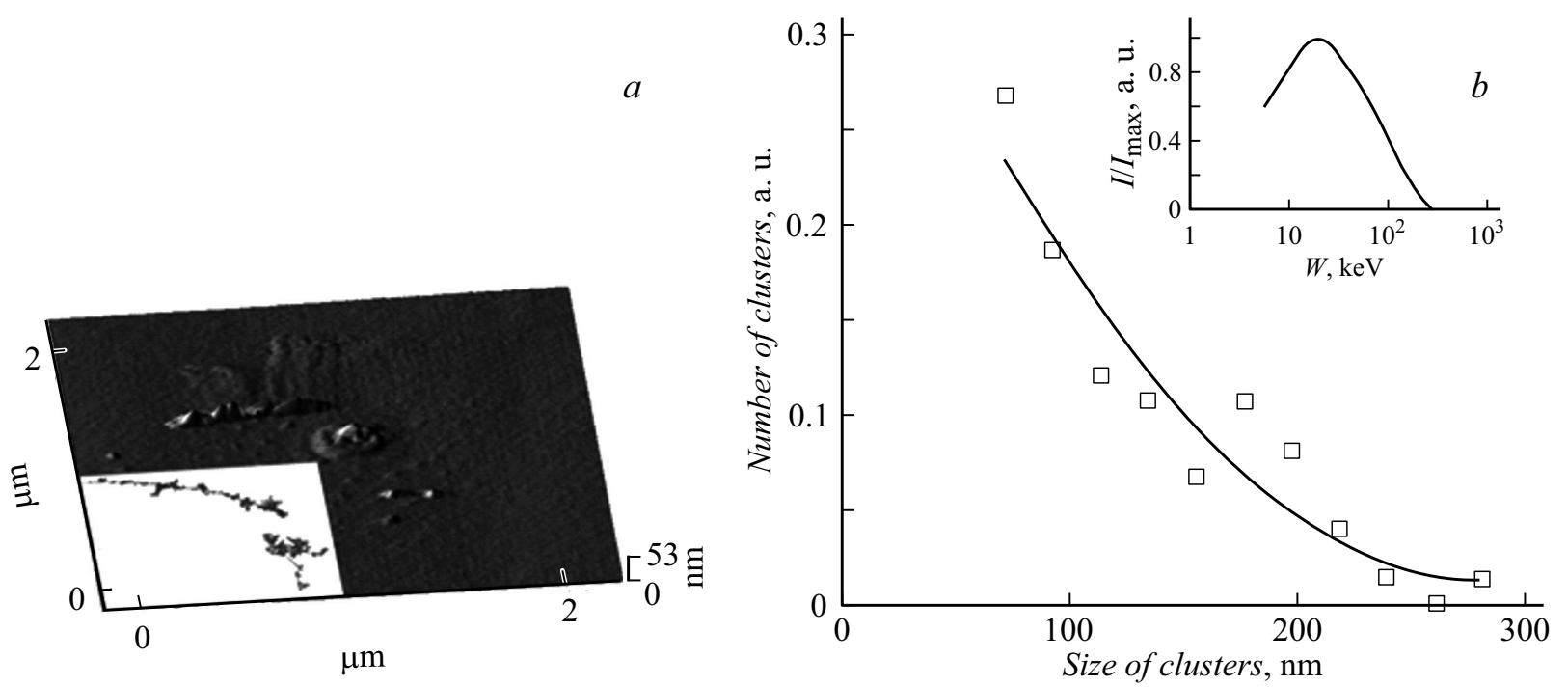

Рис. 3. Анализ распределения кластеров дефектов по размерам. $a-$ АСМ-изображение структуры кластеров радиационных дефектов. На вставке - результат моделирования в программе TRIM. $b$ - распределение по размерам кластеров радиационных дефектов, образовавшихся при облучении GaAs нейтронами: сплошная линия - расчет по TRIM, точки - зондовые измерения. На вставке показан спектр средних энергий, получаемых первичными атомами Ga при столкновениях с быстрыми нейтронами.

В результате исследований доказана работоспособность предложенного подхода к определению параметров кластеров радиационных дефектов и их распределения в целом. Результаты исследований могут быть использованы для моделирования параметров GaAs-полупроводниковых приборов после нейтронного облучения.

\section{Благодарности}

Авторы благодарят сотрудников АО НПП „Салют“ А.Г. Фефелова, Д.И. Дюкова и М.А. Кревского за предоставление образцов и полезные обсуждения.

\section{Финансирование работы}

Работа выполнена в рамках базовой части государственного задания (проект № 0729-2020-0057).

\section{Конфликт интересов}

Авторы заявляют, что у них нет конфликта интересов.

\section{Список литературы}

[1] Т.М. Агаханян, Е.Р. Аствацатурьян, П.К. Скоробогатов, Радиационные эбфекты в интегральных микросхемах (Энергоатомиздат, М., 1989).

[2] B.R. Gossick, J. Appl. Phys., 30 (8), 1214 (1959). https://doi.org/10.1063/1.1735295

[3] С.В.Оболенский, Поверхность. Рентгеновские, синхротронные и нейтронные исследования, № 7, 53 (2003).

[4] С.В. Оболенский, Микроэлектроника, 33 (2), 153 (2004).
[5] В.А. Скуратов, А.Е. Ефимов, Д.Л. Загорский, ФТТ, 44 (1), 165 (2002),

[6] Е.А. Тарасова, А.В. Хананова, С.В. Оболенский, В.Е. Земляков, Ю.Н. Свешников, В.И. Егоркин, В.А. Иванов, Г.В. Медведев, Д.С. Смотрин, ФТП, 50 (3), 331 (2016).

[7] Физические прочессы в облученных полупроводниках, под ред. Л.С. Смирнова (Наука, Новосибирск, 1977).

[8] A.B. Loginov, R.R. Ismagilov, J. Nanophoton., 11 (3), 1 (2017). https://doi.org/10.1117/1.JNP.11.032509

[9] Е.С. Вентцель, Теория вероятностей (Наука, М., 1969).

[10] И.Ю. Забавичев, А.А. Потехин, Вестн. ННГУ. Сер.: Физика твердого тела, № 1(2), 64 (2014).

[11] А.С. Пузанов, С.В. Оболенский, В.А. Козлов, в сб. Тр. Всерос. конф. „Радиационная стойкость электронных систем“ ( „стойкость-2016“) (НИЯУ МИФИ, М., 2016), c. $69-70$.

[12] А.С. Пузанов, С.В. Оболенский, в сб. Тезисы докладов VI Всерос. конф. „Физические и физико-химические основы ионной имплантации“ (ННГУ, Н. Новгород, 2016), с. 8990.

[13] J.P. Biersack, Nucl. Instrum. Meth. Phys. Res., 27 (1), 21 (1987). https://doi.org/10.1016/0168-583X(87)90005-X 